\title{
Palmar fasciitis with polyarthritis-associated ovarian cancer: Case report and literature review
}

\author{
HIROYUKI KAJIKAWA ${ }^{1}$, TAKUYA SOBAJIMA ${ }^{2}$, CHINATSU KOIWAI ${ }^{1}$, \\ SATOSHI ICHIGO $^{1}$, HIROSHI TAKAGI ${ }^{1}$ and ATSUSHI IMAI ${ }^{1}$ \\ Departments of ${ }^{1}$ Obstetrics and Gynecology, and ${ }^{2}$ General Internal Medicine, \\ Matsunami General Hospital, Kasamatsu, Gifu 501-6062, Japan
}

Received October 3, 2017; Accepted November 21, 2017

DOI: $10.3892 /$ mco.2017.1509

\begin{abstract}
Palmar fasciitis and polyarthritis (PFPA) is an uncommon disorder clinically characterized by rapidly developing bilateral arthritis of the hands and fasciitis of the palms. This cancer-associated syndrome, primarily linked to ovarian cancer, has also been associated with multiple different malignancies. PFPA symptoms usually precede the detection of ovarian cancer. In all patients from case series and single case reports described, ovarian cancer is already present at an advanced stage. Therefore, the authors aimed to present a case and systematically review available evidence on the association between PFPA and ovarian cancer, as gynecological oncologists. Awareness and recognition of PFPA may allow for earlier diagnosis and treatment of an occult ovarian cancer. The commitment of the attending gynecologists to become familiar with and identify rare diseases may lead to the detection at an early and curative stage and potentially life-saving therapeutic interventions.
\end{abstract}

\section{Contents}

1. Introduction

2. Case report

3. Literature review of PFPA-associated ovarian cancer

4. Ovarian benign tumors

5. Comments

\section{Introduction}

Palmar fasciitis with polyarthritis (PFPA) has a characteristics clinical course that involves rapidly bilateral arthritis

Correspondence to: Dr Atsushi Imai, Department of Obstetrics and Gynecology, Matsunami General Hospital, 185-1 Dendai, Kasamatsu, Gifu 501-6062, Japan

E-mail: aimai@matsunami-hsp.org.jp

Key words: palmar fasciitis, polyarthritis, ovarian cancer, cancer-associated syndrome of the hands and fasciitis of the palms $(1,2)$. This results in pain, swelling and progressive contractures of the hands. These symptoms can co-occur with less severe synovitis of distant articilations. The palmar skin generally shows nodular erythema, and nodularity of the flexor tendons is often noted. This is a rare disease, while it is important for physicians to be able to recognize the disease in the patients with theses characteristic clinical symptoms and screen for malignancy (3-5). Extensive review of underlying malignancies associated with PFPA showed ovarian cancer accounting for the majority $(37 \%)$ of the cases (6).

In the all patients from case series and single case reports described, the ovarian cancer is already present in an advanced stage. We attempted to present our case and systemically review available evidence on the association between PFPA and ovarian cancer, as gynecological oncologists.

\section{Case report}

A 61-year-old woman presented with a 1-year history of bilateral progressive painful swelling of the hands (Fig. 1) with stiffness and diffuse arthralgia in the elbows and knees. In addition, a half-year after the onset, she suffered from fatigue and reported a weight loss of $2 \mathrm{~kg}$ within the last 1-month. There was no improvement with predonisone $(15 \mathrm{mg} / \mathrm{day})$. Laboratory tests revealed a normal complete blood count, sedimentation rate, and routine chemistry results. Antinuclear antibody, extractable nuclear antigen antibodies, anti-citrulinated peptide antibodies and rheumatoid factor testing were normal. Magnetic resonance imaging (MRI) showed high-intensity nodules above the flexor tendons. However, there was no evidence of MRI findings suggestive of the existence of arthritis.

Consideration of the unusual clinical findings and the progressive palmar contracture led to possible diagnosis of palmar fasciitis. The cancer-associated disease (6-8) prompted us to screen the most frequent underlying malignancy including ovarian cancer. Abdominal MRI showed a mass of the bilateral ovary with signs of peritoneal and omental metastases (Fig. 2).

The patient was submitted to exploratory laparotomy. There was a sold, gray and brown mixed mass $(5 \mathrm{~cm})$ in the left ovary, widespread malignant deposits $(<2 \mathrm{~cm})$ within the pelvis, and omental fullness due to metastatic tumor. The right 
ovary was involved. A complete staging with hysterectomy, bilateral salpingo-ophorectomy, omentectomy was performed. Histological examination of the tissue revealed a poorly differentiated serous adenocarcinoma originated from left ovary with omental involvement and peritoneal dissemination. Cytology of ascites yielded poorly differentiated adenocarcinoma. The stage was IIIB (pT3BNxM0). The patient was expected to receive postoperative chemotherapy with carboplatin and paclitaxel. Although the patient is still under intensive chemotherapy, the dismal prognosis of this condition prompted us to review our experience with PFPA associated ovarian cancer and previous literatures. The patient provided written informed consent to study publication.

\section{Literature review of PFPA-associated ovarian cancer}

In a literature review we found 17 case series and single case reports of PFPA associated ovarian and fallopian cancers (Table I). The association between the malignancies and a PFPA condition has been dominantly in the elderly. Their age of previously reported patients was postmenopausal women, except younger 2 cases (25 and 42 years).

In over $60 \%$ of all cases, by far the most frequently occurring histological type was serous (papillary) adenocarcinoma. The poorly differentiated or undifferentiated adenocarcinoma accounted for $25 \%$, and the characterized as endometrioid only in one report (6 cases). All patients were diagnosed already in advanced stage of metastatic spreading.

PFPA symptoms preceded the diagnosis of ovarian cancer, or PFPA symptoms led to immediate detection of an underlying these cancers. Interestingly in 2 cases of 3 fallopian tube cancers, the diagnosis of underlying malignancies by laparotomy preceded the onset of PFPA symptoms by 1 year $(9,10)$. In another case of fallopian tube cancer, the diagnosis of PFPA led to the immediate detection of an underlying malignancy (11). There are many similarities between fallopian tube cancer and ovarian cancer, and ovarian cancer is believed to originate in the distal and proximal fallopian tube (12-15). Research published over the past 10 years has suggested that the most 'ovarian cancer', and specifically the high-grade serous carcinoma subtype of ovarian cancer, actually originates in the fallopian tube $(13,15)$. PFPA-associated fallopian tube cancer may be the precursor of at least ovarian serous adenocarcinoma of the ovary.

The pathophysiology of PFPA is unclear. One hypothesis involves abnormalities in humoral and immune responses associated with the malignancy and responsible for overproduction of certain cytokines $(16,17)$. Considering all reported cancer-associated syndromes and associated cancer, the majority of affected patients have been elderly women, which suggests the female hormone state may predispose to this syndrome as is the case in most autoimmune disease. The cytokines [e.g., vascular endothelial growth factor (VEGF), insulin-like growth factor (IGF), transforming growth factor $\beta$ (TGF- $\beta$ )] play an important role in ovarian stromal proliferation and emergence of ovarian cancer (18-20). Ovarian cancer and fallopian tube cancer release many types of cytokines such as VEGF, IGF, TGF- $\beta$ (20). A higher level of TGF- $\beta$ and VEGF may be a candidate to facilitate the rapid progression in the patients with PFPA associated with malignancies.

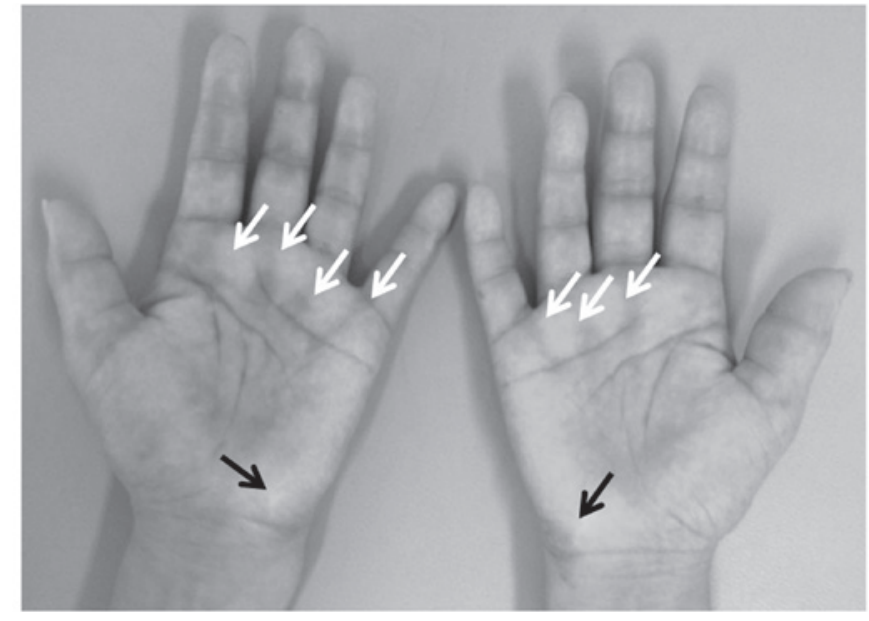

Figure 1. Palmar aspects of edema surrounding the elastic hard nodule (white arrows) and redness of the elastic hard nodules (black arrows).

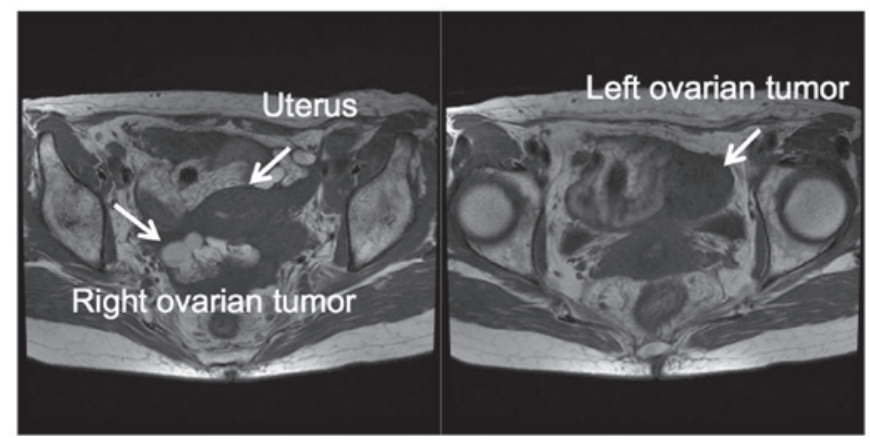

Figure 2. Abdominal T2-weighted MRI, showing evidence of bilateral ovarian tumors, peritoneal implantation and significant amount of ascites.

Treatment of the underlying cancer is paramount to the management of PFPA symptoms. Almost half of the patients reported describe a decrease in the symptoms after surgery, chemotherapy and/or radiotherapy $(6,21)$. The role of new biological agents, such as TGF inhibitors and VEGF inhibitors, in this indication remains unclear, but their immunosuppressive and anti-angiogenic properties could theoretically be detrimental and trigger cancer progression.

\section{Ovarian benign tumors}

PFPA has been implicated also with ovarian non-malignant tumors including endometrial cyst (1) and paraovarian cyst (22). As PFPA was suspected, a more complete investigation was performed in these 2 cases. Abdominal imaging demonstrated a pelvic cystic mass rising from adnexa. Currently there are no effective screening methods for ovarian cancer and the malignancies frequently remains undiagnosed until metastasis has occurred. When found in PFPA patients, the ovarian tumor highly suspected as benign should be removed and submitted to pathological examination.

\section{Comments}

Learning PFPA and its presentations in particular by gynecologic oncologist can rise the suspicion of underlying 
Table I. Fallopian tube and ovarian cancers related palmar fasciitis with polyarthritis.

\begin{tabular}{lclll}
\hline First author, year & Age (years) & & \multicolumn{1}{c}{ Stage } & (Refs.) \\
\hline A, Fallopian tube & & & \\
\hline Fukui, 2015 & $64^{\mathrm{a}}$ & Serous adenocarcinoma & pT3cNxM0 & (11) \\
Taggart, 1984 & 58 & Well differentiated adenocarcinoma & $\begin{array}{l}\text { Not described } \\
\text { (peritoneal spread) }\end{array}$ & $(10)$ \\
Denschlag, 2004 & 73 & Serous papillary adenocarcinoma & $\begin{array}{l}\text { Not described } \\
\text { (complete staging surgery } \\
\text { performed) withpartial } \\
\text { rejection of colon due to } \\
\text { tumor infiltration }\end{array}$ \\
\hline
\end{tabular}

B, Ovary

\begin{tabular}{|c|c|c|c|c|}
\hline Medsger, 1982 & $\begin{array}{l}6 \text { postmenopausal } \\
(50 \text { to } 65)\end{array}$ & Endometrial carcinoma, G2 or G3 & $\begin{array}{l}\text { Non-resectable tumor } \\
\text { and peritoneal seeding } \\
\text { in all patients. }\end{array}$ & (23) \\
\hline Martorell, 2004 & $\begin{array}{l}4 \text { postmenopausal } \\
\quad(51 \text { to } 73)\end{array}$ & Serous papillary adenocarcinoma & $\begin{array}{l}2 \text { of pT4NxM1, } 1 \text { of } \\
\text { pT3CNOM0 and } 1 \\
\text { of pT3BNOM0 }\end{array}$ & (24) \\
\hline Taggart, 1984 & 42 & Poorly differentiated adenocarcinoma & $\begin{array}{l}\text { Not described } \\
\text { (peritoneal spread) }\end{array}$ & (10) \\
\hline Yogarajah, 2008 & 74 & Poorly differentiated adenocarcinoma & $\begin{array}{l}\text { Not described } \\
\text { (peritoneal spread) }\end{array}$ & (25) \\
\hline Preda, 2009 & 62 & Poorly differentiated adenocarcinoma & Inoperable & (16) \\
\hline Strobel, 1992 & 59 & Serous adenocarcinoma & pT3CN1M0 & (26) \\
\hline Salmon, 2013 & $\begin{array}{l}2 \text { postmenopausal } \\
\text { (58 and 69) }\end{array}$ & $\begin{array}{l}\text { Serous adenocarcinoma } \\
\text { and adenocarcinoma }\end{array}$ & $\begin{array}{l}\text { pT3BN0M0 and T3CNxM0 } \\
\text { (not operated) }\end{array}$ & (27) \\
\hline Pfinsgraff, 1986 & 57 & Adenocarcinoma & T4NxM1 & (28) \\
\hline Bremer, 1967 & 50 & Not identified & T4NxM1 & (29) \\
\hline Van Marcke, 2017 & 70 & Serous adenocarcinoma & pT3CN1M0 & (21) \\
\hline Qureshi, 2011 & 73 & Serous adenocarcinoma & pT3CNxM0 & (7) \\
\hline Manger, 2014 & 73 & Serous adenocarcinoma & pT3CNxM0 & $(6)$ \\
\hline Vinker, 1996 & 25 & Serous papillary adenocarcinoma & Stage IV & (30) \\
\hline Shiel, 1985 & $\begin{array}{l}75 \\
61\end{array}$ & $\begin{array}{l}\text { Serous adenocarcinoma } \\
\text { Serous adenocarcinoma }\end{array}$ & $\begin{array}{l}\text { Stage IV } \\
\text { pT3BNxM0 }\end{array}$ & $\begin{array}{l}(31) \\
\text { Present } \\
\text { case }\end{array}$ \\
\hline
\end{tabular}

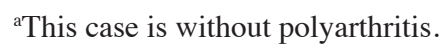

ovarian/fallopian cancer. The commitment of the attending physicians to become familiar with and identify rare disease may lead to the detection at an early and curative stage. As the symptoms of PFPA can usually precede cancer detection, and are unrelated to tumor stage, rapid diagnosis of PFPA can expedite effective management of the malignancy. Currently there are no effective screening methods for ovarian cancer and the malignancies frequently remains undiagnosed until advance stage. We recommend a thorough malignancy work-up by gynecological oncologist for any women presenting with the sudden onset of unexplained hand pain, inflammatory fasciitis, or palmar fibromatosis.

\section{References}

1. Champion GD, Saxon JA and Kossard S: The syndrome of palmar fibromatosis (fasciitis) and polyarthritis. J Rheumatol 14: 1196-1198, 1987.

2. Alexandroff AB, Hazleman BL, Matthewson M, Black CM, Rytina E, Crawford R and Burrows NP: Woody hands. Lancet 361: 1344, 2003. 
3. Haroon M and Phelan M: A paraneoplastic case of palmar fasciitis and polyarthritis syndrome. Nat Clin Pract Rheumatol 4: 274-277, 2008

4. Azar L and Khasnis A: Paraneoplastic rheumatologic syndromes. Curr Opin Rheumatol 25: 44-49, 2013.

5. Baron M: Palmar fasciitis, polyarthritis and carcinoma. Ann Intern Med 97: 616, 1982

6. Manger B and Schett G: Palmar fasciitis and polyarthritis syndrome-systematic literature review of 100 cases. Semin Arthritis Rheum 44: 105-111, 2014.

7. Qureshi AA and Saavedra A: Palmar fasciitis and polyarthritis syndrome in patients with ovarian cancer-a case report and review of the literature. Hand(N Y) 6: 220-223, 2011.

8. Scheinfeld N: A review of the cutaneous paraneoplastic associations and metastatic presentations of ovarian carcinoma. Clin Exp Dermatol 33: 10-15, 2008.

9. Denschlag D, Riener E, Vaith P, Tempfer C and Keck C: Palmar fasciitis and polyarthritis as a paraneoplastic syndrome associated with tubal carcinoma: A case report. Ann Rheum Dis 63 : $1177-1178,2004$

10. Taggart AJ, Iveson JM and Wright V: Shoulder-hand syndrome and symmetrical arthralgia in patients with tubo-ovarian carcinoma. Ann Rheum Dis 43: 391-393, 1984.

11. Fukui S, Fujiwara S, Kobayashi S, Kamei S, Takizawa Y, Setoguchi K, Uno M and Funata N: Fallopian tube cancer with palmar fibromatosis or fasciitis without polyarthritis. Intern Med 54: 2409-2414, 2015.

12. Carlson JW, Miron A, Jarboe EA, Parast MM, Hirsch MS Lee Y, Muto MG, Kindelberger D and Crum CP: Serous tubal intraepithelial carcinoma: Its potential role in primary peritoneal serous carcinoma and serous cancer prevention. J Clin Oncol 26 : 4160-4165, 2008.

13. Dietl J: Revisiting the pathogenesis of ovarian cancer: The central role of the fallopian tube. Arch Gynecol Obstet 289: 241-246, 2014.

14. Lee Y, Miron A, Drapkin R, Nucci MR, Medeiros F, Saleemuddin A, Garber J, Birch C, Mou H, Gordon RW, et al: A candidate precursor to serous carcinoma that originates in the distal fallopian tube. J Pathol 211: 26-35, 2007.

15. Reade CJ, McVey RM, Tone AA, Finlayson SJ, McAlpine JN, Fung-Kee-Fung $M$ and Ferguson SE: The fallopian tube as the origin of high grade serous ovarian cancer: Review of a paradigm shift. J Obstet Gynaecol Can 36: 133-140, 2014.

16. Preda V, Frederiksen P and Kossard S: Indurated reticulate palmar erythema as a sign of paraneoplastic palmar fasciitis and polyarthritis syndrome. Australas J Dermatol 50: 198-201, 2009.

17. Mehra S, Walker J, Patterson K and Fritzler MJ: Autoantibodies in systemic sclerosis. Autoimmun Rev 12: 340-354, 2013.

18. Emori $\mathrm{C}$ and Sugiura K: Role of oocyte-derived paracrine factors in follicular development. Anim Sci J 85: 627-633, 2014.
19. Geva E and Jaffe RB: Role of vascular endothelial growth factor in ovarian physiology and pathology. Fertil Steril 74: 429-438, 2000.

20. Imai A, Ichigo S, Matsunami K, Takagi $H$ and Kawabata I: Ovarian function following targeted anti-angiogenic therapy with bevacizumab. Mol Clin Oncol 6: 807-810, 2017

21. van Marcke C, Seront E, Docquier C and Filleul B: Palmar fasciitis and polyarthritis, a rare paraneoplastic syndrome related to ovarian cancer. Clin Exp Dermatol 42: 328-330, 2017.

22. Fernandez-Nebro A, Fernandez-Ruiz A, Rodriguez M, Haro M, Rodriguez-Andreu J and Gonzalez-Santos P: Palmar fasciitis and polyarthritis syndrome is multicausal. Clin Rheumatol 15 99-101, 1996

23. Medsger TA, Dixon JA and Garwood VF: Palmar fasciitis and polyarthritis associated with ovarian carcinoma. Ann Intern Med 96: 424-431, 1982.

24. Martorell EA, Murray PM, Peterson JJ, Menke DM and Calamia KT: Palmar fasciitis and arthritis syndrome associated with metastatic ovarian carcinoma: A report of four cases. J Hand Surg Am.29: 654-660, 2004.

25. Yogarajah M, Soh J, Lord B, Goddard N and Stratton R: Palmar fasciitis and polyarthritis syndrome: A sign of ovarian malignancy. J R Soc Med 101: 473-475, 2008.

26. Strobel ES, Lacour M and Peter HH: Palmar fascial thickening and contractures of fingers resembling arthritis-a paraneoplastic symptom? Rheumatol Int 12: 79-80, 1992.

27. Salmon C, Gill G, Loeuille D and Chary-Valckenaere I: Three new cases of palmar fasciitis with polyarthritis including a patient with atypical mutilating osteolysis. Joint Bone Spine 80: 217-220, 2013.

28. Pfinsgraff J, Buckingham RB, Killian PJ, Keister SR, Brereton WF, Weinblatt ME, George DL and Arnett FC: Palmar fasciitis and arthritis with malignant neoplasms: A paraneoplastic syndrome. Semin Arthritis Rheum 16: 118-125, 1986.

29. Bremer C: Shoulder-hand syndrome. A case of unusual aetiology. Ann Phys Med 9: 168-171, 1967.

30. Vinker S, Dgani R, Lifschitz-Mercer B, Sthoeger ZM and Green L: Palmar fasciitis and polyarthritis associated with ovarian carcinoma in a young patient. A case report and review of the literature. Clin Rheumatol 15: 495-497, 1996.

31. Shiel WJ, Prete PE, Jason M and Andrews BS: Palmar fasciitis and arthritis with ovarian and non-ovarian carcinomas. New syndrome. Am J Med 79: 640-644, 1985. 